2. ALGUNOS PROBLEMAS INTERPRETATIVOS DEL ARTICULO 86 DE LA CONSTITUCIÓN ESPAÑOLA

PABLO SANTOLAYA MACHETTI

Profesor Titular de Derecho Constitucional Universidad Complutense. Madrid 
SUMARIO

NOTA PREVIA.-I. ANALISIS DEL PRESUPUESTO HABILITANTE.-II. LIMITES MATERIALES DE LOS DECRETOS LEYES.1. Derivados de las instituciones básicas del Estado. 2. Derechos, Deberes y Libertades de los ciudadanos regulados en el Título I. 3. Régimen de las Comunidades Autónomas. 4. Derecho electoral general.-III.-INTERVENCION PARLAMENTARIA.-IV.-CONTROL POR EL TRIBUNAL CONSTITUCIONAL.-V. UTILIZACION DE LOS DECRETOS-LEYES EN LA II LEGISLATURA.-CONCLUSION. 


\title{
2. ALGUNOS PROBLEMAS INTERPRETATIVOS DEL ARTICULO 86 DE LA CONSTITUCIÓN ESPAÑOLA
}

\author{
PABLO SANTOLAYA MACHETTI
}

Profesor Titular de Derecho Constitucional

Universidad Complutense. Madrid

\author{
NOTA PREVIA *
}

El presente trabajo no pretende en modo alguno agotar la importante problemática que presenta la figura de los Decretos-Leyes, sino sólo reflejar algunos de sus aspectos más llamativos y aportar, en la medida de lo posible, soluciones interpretativas. Su carácter parcial e inevitablemente fraccionario puede quedar en parte justificado por tratarse de la transcripción de una exposición oral sobre un texto mucho más amplio que será próximamente publicado.

Partiendo de estas premisas, se detiene en el análisis del presupuesto habilitante, los límites materiales, la intervención parlamentaria y

* Con carácter general para el estudio de los Decretos-Leyes ver: I. AstARLoA HUARTE, «Comentario al artículo 86", en Comentarios a las Leyes Politicas. O. Alzaga. Tomo VII. Edersa, Madrid, 1985. págs. 137 y ss. P. CRUz ViLLALON, «Tres sentencias sobre el DecretoLey", en El Gobierno en la Constitución española y los Estatutos de Autonomia. Diputación de Barcelona. Barcelona 1985. págs. 145 y ss. F. Cuocolo, "Gli atti dello Stato aventi forza di legge", en Rivista trimestrale di Diritto Pubblico. 1961. pág. 97 y ss. V. Dı Cılo, Questioni in tema di Decreti-leggi. Tomo I. Giufré. Milano 1970. C. Esposito, Voz Decreto-Legge, en Enciclopedia del Diritto. 1962. págs. 831 y ss. Garcla DE ENTERRIA /FERnAnDEz, Curso de Derecho Administrativo. Vol I. 4. ed. Civitas. Madrid, 1983, especialmente págs. 160 y ss. y 831 y ss. MORISI/CAZZOLA, "La decisione urgente. Usi e funzione del decreto-legge nel sistema italiano", en Rivista Italiana de Scienza Politica. 3/81. pág. 446 y ss. L. PALAdIN, «Comentario al art. 77» en G. Branca. Zanichelli/ll foro. 1979. págs. 42 y ss. y «In tema di decretilegge, en Riv. Trim. Dir. Pubb. 1958. págs. 533 y ss. J. PÉREz RoYo, «La distribución de la capacidad normativa entre el Parlamento y el Gobierno"; en El gobierno en la... cit. págs. 93 y ss. y Las fuentes del Derecho. Tecnos. Madrid. 2." ed. 1985. págs. 102 y ss. J. SALAS, Los Decretos-leyes en la Constitución española de 1978. Cuadernos Civitas. Madrid 1979. J. E. SoRIANo, «Los Decretosleyes en la jurisprudencia constitucional española". R.A.P. 100-102. Vol !. pág. 453 y ss. F. SorRentino, "Le fonti del diritto pubblico", en Manuale di Diritto Pubblico, a cura di Amato/ Barbera. II Mulino. Bologna 1984. págs. 135 y ss. G. VIESTI, // Decreto-Legge. E. Jovene. Napoli 1967. 
el control por el Tribunal Constitucional, concluyendo con un breve apéndice en el que se analiza la utilización de los Decretos-Leyes en la II Legislatura.

\section{ANÁLISIS DEL PRESUPUESTO HABILITANTE}

El artículo 86 de la Constitución española establece como presupuesto habilitante para la producción de Decretos-Leyes la existencia de un "caso extraordinaria y urgente necesidad", y, con una locución similar, el artículo 77 de la Constitución italiana se refiere a «Casos extraordinarios de urgencia y necesidad".

El punto de partida que se adopta para el análisis de esta expresión es considerar que el concepto «extraordinario» carece de valor autónomo con respecto a la «necesidad y urgencia», sirviendo únicamente para recalcar el carácter "no normal» de esta específica forma de producción normativa, que estaria definida por su «necesidad y urgencia»'.

¿Qué se entiende por "necesidad»? En términos formales hace referencia, como ha señalado SORIANO, a una situación en la cual la no actuación gubernamental provocaría un mal para el interés social; sin embargo lo trascendente es delimitar cuándo puede surgir esa necesidad, si se trata de un dato plenamente objetivo, en relación a determinadas circunstancias consideradas universalmente como tales (arquetípicamente los casos de catástrofes naturales) o por el contrario es defendible su aplicación a necesidades relativas, que lo son exclusivamente desde la óptica de una determinada idea política o programa de gobierno.

La jurisprudencia constitucional en España se ha pronunciado claramente por la defensa de un concepto de «necesidad relativa», utilizando la terminología de ESPOSITO, lo que configura al Decreto-Ley, desde el punto de vista de su «necesidad», no como un instrumento excepcional, sino simplemente como algo «no normal», utilizable en relación a concretos objetivos político-gubernamentales, como ha señalado la STC 6/83 de 4 del II, marcando una línea jurisprudencial seguida sin excepciones hasta el momento.

1 Análisis más o menos detallados del significado de los tres términos se pueden encontrar en M. RAVERAIRA, «Il problema del sindacato di constituzionalitá sui presupposti della "necessitá" "urgenza" dei Decreti-leggi», en Giurisprudenza Costituzionale. 1982 I. págs. 1433 y ss. V. Di CIolo, Questioni... cit. pág. 217 y ss. S. Foderado, Manuale di Diritto Pubblico. CEDAM. Padova. 4." ed. 1977 págs. 173 y ss. J. E. SORIANo, «Algunos problemas prácticos del decreto-ley. En torno a la Sentencia del Tribunal Constitucional de 31.V.82m, en E. LiNDE, Materiales para el estudio de la Constitución española. Aranzadi. Pamplona 1983. págs. 1094 y ss. 
En este sentido se han admitido necesidades tan genéricas como «la permanencia de una coyuntura económica de crisis industrial» (STC 29/ 86 de 20.II) o tan poco «extraordinarias» en una democracia como «la celebración de elecciones y la alternancia en el poder" (STC 6/86 de 20.V). De ello se derivan dos consecuencias:

- Una interpretación tendencialmente «francesa» del presupuesto habilitante, en cuyo ordenamiento, en virtud del artículo 38, se configura como tal «el ejercicio del programa gubernamental».

- Una inversión de los términos de la pregunta; no se trata de saber cuándo existe una situación de necesidad que permita la utilización de los Decretos-Leyes, sino más bien la contraria, si existe alguna que provocaría su ilicitud jurídica.

¿Qué se entiende por «urgencia»? Existe una respuesta desconcertantemente simple realizada ya en la Asamblea Constituyente italiana por TOMASSINI: «Cuando el desarrollo del procedimiento ordinario, incluso el abreviado, no permite el logro tempestivo de una finalidad propuesta por el Gobierno" ?.

Así la urgencia se convierte en un concepto relacional, depende de la imposibilidad del Parlamento para adoptar ese acto como propio, para introducir los contenidos materiales de los Decretos-Leyes en una Ley formal, y en este sentido se han pronunciado numerosas sentencias de nuestro Tribunal Constitucional (29/82 de 31 del V, 6/83 de 4 del II, 111/83 de 2 del XII...).

Al margen de este concepto relacional, que es el fundamental, se pueden obtener dos notas aparentemente claras que delimitan el concepto de «urgencia»:

- Tiene que tratarse de una materia sometida a una reserva formal o material de ley, y por lo tanto en circunstancias normales debe ser regulada por las Cortes Generales.

- Las medidas previstas tienen que tener una eficacia inmediata, es decir estar produciendo plenamente sus efectos en un tiempo menor que el que llevaría, en concreto, su tramitación como Ley.

2 La intervención de Tomassini en la Asamblea constituyente Italiana está tomada del trabajo de F. CAzzOLA, "La lentezza dell' urgenza», en CAzzolA y otros / Decreto-legge fra goberno e Parlamento. Giuffré. Milano 1975, pág. 8. 
Pero estas dos notas tienen que ser inmediatamente matizadas:

En primer lugar, y en base a la «inexistencia de una reserva reglamentaria", nuestra jurisprudencia constitucional (STC 60/86 de $20 \mathrm{del} V$ ) ha admitido la posibilidad de "elevar de rango" mediante Decreto-Ley materias anteriormente tratadas reglamentariamente, doctrina que entiendo criticable entre otras razones porque parece que en ningún caso se puede hablar en este supuesto de "urgencia y necesidad» como causa justificativa para sustituir la normal actividad parlamentaria.

En segundo lugar parece que es posible admitir una cierta distinción entre la urgencia de la adopción de las medidas y la urgencia de las propias medidas, siguiendo la terminología de ESPOSITO entre la urgencia del "provvedimento" y la del «provvedere» ${ }^{3}$, que puede llevar a justificar la actuación normativa separada temporalmente de las circunstancias materiales, considerando "urgentes" Decretos-Leyes cuyos efectos se dilatan en el tiempo o que tratan de satisfacer necesidades surgidas con mucha anterioridad.

Asi el Real Decreto-Ley $9 / 84$, de 13 de julio establece efectos retroactivos para los sueldos de determinados funcionarios, y el 14/81, de 20 de agosto retrasa su entrada en vigor dos meses. Todo ello parece posible en nuestro sistema constitucional con el único límite de no admitir un precepto exclusivamente deslegalizador (STC 39/82 de $31 \mathrm{del}$ V) y de que las medidas materiales estén adoptadas, de hecho, en un plazo menor al que supondría su aprobación por las Cortes (STC 29/86 de 20 del II). tante?

¿Cuáles son los límites en la apreciación del presupuesto habili-

Nuestra Jurisprudencia Constitucional ha establecido los siguientes parámetros a la hora de delimitar la acción gubernamental:

1. Afirmación del carácter jurídico de los límites del artículo 86 , controlables como tales por el Tribunal Constitucional. (p.ej STC 29/82 de 31.V)

2. Importancia esencial de la definición realizada por el Gobierno, que cuenta en este sentido con amplios márgenes de discreccionalidad. (p.ej STC 111/83 de 2 del XI)

3 La doctrina de la diferencia entre la urgencia del provvedere y del provvedimento proviene del trabajo de Esposito, "Decreto-legge» cit., pág. 844, aunque ya la habia esbozado con anterioridad en La validitá degli leggi. Giuffré. Milano 1934. A favor de esta teoría se han pronunciado G. VIESTI, // decreto... cit., pág. 126. C. MoRTATI, Istituzioni di Diritto Pubblico. Tomo II. CEDAM. Padova. 9. ed. 1976 pág. 707. F. SoRRENTINo, “La Corte Costituzionale tra decretolegge e legge di conversione: Spunti ricostructtivi», en Diritto e societá. 1974 pág. 533 y ss. Posturas críticas a esta doctrina se pueden ver, entre otras en M. RAVERAIRA, "ll problema..." cit. pág. 1433 y ss. 
3. Limitación de la actividad del Tribunal a los supuestos de uso abusivo o arbitrario por parte del Gobierno, es decir, con VIESTI, a aquellos casos en los que la falta de presupuesto se presenta sub especie de exceso de poder legislativo.

4. Se puede hablar sin embargo de un «juicio de razonabilidad» sobre la acción del Gobierno, mediante la existencia de una serie de parámetros utilizables por el Tribunal. Por ejemplo, cierta imprevisibilidad de las circunstancias, intervalos temporales entre las distiptas fases de producción de la norma, motivación formal...

5. Por último se pueden señalar dos datos significativos: a pesar de que la inexistencia de «urgencia y necesidad» ha sido alegada en la totalidad de los recursos, hasta ahora no se ha producido ninguna declaración de inconstitucionalidad por ausencia de estos requisitos, $y$, lo que es más importante, en todos ellos el Tribunal ha utilizado como criterio para apreciar la constitucionalidad la exposición de motivos del texto gubernamental, con lo que parece consumarse un curioso fenómeno de inversión de carga de la prueba; cualquier definición es válida siempre que no la desvirtúen los recurrentes del proceso constitucional.

En estas circunstancias es dificil determinar si nos encontramos ante un supuesto de "concepto jurídico indeterminado" (GARCIA DE ENTERRIA/ FERNANDEZ, SALAS) o ante una potestad discrecional (PEREZ ROYO), entre otras cosas porque la distinción entre ambos no es tan clara como ha pretendido la doctrina ${ }^{4}$.

Aparentemente nos encontramos en una situación intermedia, a la que quizás se pudiera aplicar el rótulo de "concepto jurídico indeterminado" si realizamos de él una interpretación «no administrativista», es decir, si partimos de que se trata de un acto producido con una espécifica habilitación constitucional por el órgano encargado de definir la política general y controlado por el que representa la soberanía popular.

Un último problema es analizar el significado de la «provisionalidad» que habilita la «urgencia y necesidad». En concreto si esta nota se refiere

- Sobre la distinción entre los conceptos jurídicos indeterminados, la discreccionalidad y su aplicación al presupuesto de los decretos-leyes vid: GARCIA DE ENTERRIA/FERNANDEZ, Curso... cit. págs. 430 y ss. L. Segura GuImard, «El control de los decretos-leyes por el Tribunal Constitucional. A propósito de la STC 2 de diciembre de 1983 recaída sobre el caso RUMASA". RAP 104. págs. 355 y ss. A. BLASCO, «Principios de jurisprudencia constitucional sobre los decretos-leyes», REDA 36. págs. 111 y ss. y J. PEREZ RoYo, «La distribución...» cit. págs. 139 yss. 
exclusivamente al instrumento normativo, al acto jurídico, o también a su contenido material, a sus prescripciones, que estarian en si mismas aquejadas de una cierta provisionalidad, no pudiendo pretender regular situaciones con carácter definitivo.

La inmensa mayoría de la doctrina, con excepción de LAVAGNA ${ }^{5}$, se ha pronunciado de forma terminante por definir la provisionalidad como una nota característica de la manifestación de voluntad del acto normativo y no de su contenido material.

El problema ha surgido en España en relación a la vigencia de los Decretos-Leyes simplemente convalidados por el Congreso. Aparentemente una vez producido este acto cesa la "provisionalidad" y por tanto su contenido es tan estable como el de las demás normas con rango de Ley. Es más, este parece ser el sentido de la convalidación a la que no sigue su posterior tramitación como Ley.

Sin embargo las STC $6 / 83$ de 4 del II y 60/86 de 20 del $V$ han creado la doctrina de la «inconstitucionalidad sobrevenida», según la cual:

- La provisionalidad de los contenidos materiales forma parte esencial de los Decretos-Leyes, es decir, que no se puede pretender una regulación «estable» mediante este instrumento normativo.

- El presupuesto habilitante ha de mantenerse «vigente» durante todo el tiempo de vigencia de la norma "provisional», que sólo puede tener eficacia mientras las circunstancias continúen siendo "extraordinarias y urgentes", ya que está sometida a una «sobrevenida falta de adecuación entre la situación habilitante y la normativa producida", que provocaria su inconstitucionalidad.

Esta tesis presenta numerosos problemas. Entre ellos quizás el de mayor importancia es que pierde sentido la institución de la convalidación en relación al sistema de fuentes, ya que si está claro que no produce la conversión en Ley del Decreto-Ley, tampoco, en virtud de esta tesis, se puede admitir que le haga perder, al menos en términos absolutos, su carácter provisional, con lo que quedan notablemente oscurecidos sus auténticos efectos.

5 Sobre la doctrina de que la provisionalidad de los decretos-leyes afecta solo a su aspecto de actos normativos pero no a su contenido material, vid. C. EsPosito, "Decretolegge», cit. pág. 844 y ss. L. PALADIN, "In tema...» cit. pág. 527 y ss. J. SALAS, Los Decretoslegges... cit. pág. 41 y A. PIzzorusso, Lecciones de Derecho Constitucional. CEC. Madrid 1984. Tomo II págs. 41 y ss. La opinión contraria es defendida por C. LAVAGNA en sus Istituzioni di Diritto Pubblico. UTET. Torino. 5. ed. 1982. págs. 322 y ss. 


\section{LÍMITES MATERIALES DE LOS DECRETOS-LEYES}

El artículo 86.1 afirma que los Decretos-Leyes no podrán «afectar» al ordenamiento de las instituciones básicas del Estado, a los derechos, deberes y libertades de los ciudadanos regulados en el Título I, al régimen de las Comunidades Autónomas ni al Derecho electoral general.

El establecimiento de una serie de límites expresos a la actuación mediante Decretos-Leyes presenta una doble y aparentemente contradictoria problemática.

En primer lugar, porque debido a la tendencia expansiva de este tipo de normas, serán casi inevitablemente superados. Hay que recordar a estos efectos la experiencia italiana, en cuya Asamblea Constituyente Mortati propuso hacer un listado de campos en los que sería lícita la utilización de este tipo de normas gubernamentales, y recibió un encargo en este sentido, renunciando al poco tiempo declarando la imposibilidad fáctica de tal limitación.

En segundo lugar, y en sentido contrario, porque además de los expresamente derivados del artículo 86, existen toda una serie de límites implicitos en la Constitución.

El tratamiento de los límites constitucionales de los Decretos-Leyes parte en el trabajo del siguiente esquema:

En principio es regulable mediante Decreto-Ley cualquier materia que la Constitución atribuye «en circunstancias normales» a las Cortes Generales, y que éstas ejercitan mediante el procedimiento de la Ley ordinaria $^{6}$.

Esto quiere decir, en sentido positivo, que los Decretos-Leyes tienen los mismos límites que las Leyes ordinarias, y en sentido negativo que allí donde se prevé un procedimiento específico de elaboración de la norma, que imposibilita su tramitación ordinaria, tampoco se podrá hacer uso de los Decretos-leyes. En el caso español, en primer lugar en las materias de Ley orgánica, pero también, por ejemplo, las sometidas a los procedimientos de reforma constitucional, las previstas en el artículo 74, la potestad reglamentaria de los órganos parlamentarios, las relacionadas con los Estados excepcionales, las que deben regular las Comunidades autónomas en virtud del reparto competencial...

- La tesis de que los límites de los Decretos-leyes son los mismos que los de las leyes ha sido expuesta en Italia entre otros por G. VIESTI, // decreto-legge... cit. pág. 83 y ss. C. Mortatı, Istittuzioni... cit. pág. 707 y ss. F. SoRREntino, “Le fonti...» cit. pág. 83 y ss. A. Pizzorusso, Lecciones... cit. pág. 271. 
No se puede sin embargo actuar mediante Decretos-Leyes en aquellas materias ejercidas por las Cortes mediante Ley ordinaria en la que materialmente se contienen mecanismos de control de la acción gubernamental "; entre ellas se pueden citar las delegaciones legislativas del artículo 82, la aprobación de los Presupuestos; la autorización para emitir deuda pública, y por supuesto la tramitación como Ley de un DecretoLey tal como prevé el 86,3 de la Constitución.

Existen, por último, una serie de límites específicos derivados del artículo 86,1, alguno de los cuales, aunque sólo una minoria, no son encajables en ninguno de los dos tipos anteriores. Siguiendo su enunciado tenemos que distinguir:

\section{Derivados de las instituciones básicas del Estado}

Nos encontramos ante un concepto indefinido, ya que en ningún artículo de la Constitución se específica cuáles son dichas instituciones.

Cabía en principio dos vías de interpretación; o identificarlas con los “órganos constitucionales" (art. 59 Ley Orgánica Tribunal Constitucional) o con los llamados «órganos de relevancia constitucional». Sin embargo, la doctrina orientó su discusión en un sentido distinto, centrándose en un problema colateral; el de si su desarrollo legal era por vía de ley ordinaria o de Ley orgánica.

Así los que defendian la equiparación entre exclusión de los decretos-leyes y materias orgánicas se veían obligados a admitir por ejemplo que el Consejo de Estado era una institución básica, en cuanto su desarrollo requiere una Ley orgánica, y que sin embargo no lo era el Gobierno, claramente un órgano constitucional.

En sentido contrario, los que no admitían la equiparación, pasaron a defender que todas las instituciones públicas, sea cual sea su papel material y su relación con otros órganos eran «instituciones básicas del Estado», siempre que estuvieran previstas en la Constitución.

7 La exclusión de los Decretos-Leyes de aquellas materias que contienen una acción de control por parte del Parlamento ha sido puesta de manifiesto por G. VIESTI, // Decreto... pág. 96 y ss, señalando que no son utilizables para aprobar el Presupuesto, los Tratados internacionales, la delegación legislativa y las deslegalizaciones. En el mismo sentido $F$. SORRENTINO, "Le fonti..." pág. 60 habla de límites derivados de la sujeción del Gobierno al control político parlamentario e indica exactamente los mismos supuestos. A. Pizzorusso, Lecciones... pág. 271 se refiere a «aquellos límites implícitamente deducibles del hecho de que los Decretos-Leyes son actos del poder ejecutivo". I. AsTARLOA habla de "materias reservadas a leyes o actos legislativos de las Cortes", Comentario... cit. págs. 174 y ss. y J. SaLAs se refiere a «materias no regulables y procedimientos legislativos implícitamente no sustituibles por Decreto-Ley". Los Decretos... cit. págs. 62 y ss. 
Este último punto de vista ha sido el aceptado por nuestra Jurisprudencia Constitucional (STC 60/86 de $20 \mathrm{del}$ V) que las ha definido como «aquellas organizaciones públicas sancionadas en el propio Texto constitucional cuya regulación reclama una Ley», utilizando por tanto el criterio de distinción expuesto por MORTATI ${ }^{8}$ entre órganos inmediatos y órganos derivados. En este sentido hay que señalar:

La inmensa mayoría de estos órganos estaban ya excluidos de su tratamiento mediante Decreto-Ley en virtud de la reserva de Ley orgánica.

Uno de los órganos a los que afecta esta ulterior restricción, el Gobierno, es claramente un órgano constitucional y como tal, indiscutiblemente, una «institución básica del Estado».

Algún otro de los ahora excluidos, como el Ministerio Fiscal o el Consejo Económico y social del artículo 131 de la Constitución, difícilmente pueden ser considerados órganos constitucionales, como lo demuestra el hecho de que el último de ellos ni siquiera existe, sin que aparentemente se resienta en absoluto nuestra forma de Gobierno.

En definitiva en esta primera exclusión material se ha optado por el criterio más amplio posible, identificándola con todas aquellas instituciones públicas previstas en la Constitución. Con ello es necesario preguntarse si el adjetivo «básicas» sigue conservando algún sentido, y si la respuesta es negativa, si esto era lo pretendido por el Texto Constitucional.

\section{Derechos, Deberes y Libertades de los ciudadanos regulados en el Título I}

Es uno de los límites más difíciles de interpretar, por las importantes consecuencias que se derivan de la adopción de uno de los tres criterios posibles:

a) Identificarlos con las materias de Ley orgánica, es decir con los «Derechos fundamentales y Libertades públicas».

b) Añadir el artículo 14 y toda la Sección II, incluyendo aspectos tan conflictivos como la materia fiscal (art. 31), la propiedad pri-

- Sobre la conceptualización de los Organos Constitucionales vid. C. MORTATI, Istituzioni. Tomo I, pág. 206 y ss. P. LuCAs Verdu, Curso de Derecho Politico. Tomo II. Tecnos. Madrid. 3." ed. 1981. págs. 172 y ss. sobre la problemática de los Organos Constitucionales en España en relación a los conflictos, vid el trabajo de J. GaRcla RocA, El conflicto entre órganos constitucionales. Tecnos. Madrid, 1987. 
vada (art. 33) y la libertad de empresa (art. 38), campos característicos de intervención de los Decretos-leyes tanto en el Derecho comparado como en la práctica española.

c) Añadir, además, los artículos comprendidos en el Título III definidos como "derechos", por ejemplo a la salud (art. 43) al medio ambiente (art. 45)...

El Tribunal Constitucional, en sus STC 6/83 de 4 del II y 111/83 de 2 del XII ha rechazado rotundamente la primera de las interpretaciones, refiriendo la expresión a la totalidad de los Derechos, Deberes y Libertades de los ciudadanos, incluyendo probablemente los que en el Capítulo III tienen esa condición, es decir que se ha optado, una vez más por el criterio más amplio posible.

\section{Régimen de las Comunidades Autónomas}

Por una parte hay que señalar que este es el epigrafe en el que más claramente aparece la distinción con respecto a las materias orgánicas del artículo 81; parece evidente que esta expresión es un término más extenso que el de "Estatutos de Autonomía».

Sin embargo no resulta en absoluto fácil precisar el concepto; la única Sentencia que se ha referido al tema, la 29/86, de $20 \mathrm{del} I 1$, dista mucho de aclarar el problema cuando afirma que «debe interpretarse en el sentido de que el Decreto-Ley no puede afectar al régimen constitucional de las Comunidades autónomas, incluida la posición institucional que les otorga la Constitución".

Parece claro en primer lugar que está excluido el contenido estatutario, previsto en el artículo 147,2 de la Constitución, incluidas por supuesto las competencias en ellos establecidas, pero desde este punto de vista la reserva no añadiria nada a la prohibición general de actuación mediante Decreto-Ley en materia orgánica.

Tampoco parece que se puedan utilizar los Decretos-Leyes para modificaciones competenciales por ninguno de los procedimientos previstos en el artículo 150 de la Constitución, porque todos ellos prevén específicas formas de elaboración.

Se ha discutido por la doctrina ${ }^{9}$ si pueden ser utilizados para una delimitación material indirecta de competencias, mediante el desarrollo de

- Con respecto a los Decretos-Leyes como posible técnica de delimitación de competencias de las Comunidades Autónomas, vid, en contra J. SALAS, Los Decretos... cit., pág. 59 y a favor I. Astarloa, Comentario cit. pág. 180. 
las bases estatales del artículo 149.1, siempre, claro está, que éstas tengan que ser definidas por una Ley. A pesar de que el artículo 67 de la Ley Orgánica del Tribunal Constitucional así parece afirmarlo, entiendo que tal actuación no es posible, y que la única norma con rango de Ley que puede hacerlo son los Decretos legislativos, en cuanto que constitucionalmente sólo tienen vedados los campos de Ley orgánica, y por tanto se afirma la exclusión de los Decretos-Leyes de toda norma delimitadora de competencias, y que ésta es precisamente la virtualidad de la locución «régimen de las Comunidades autónomas».

\section{Derecho electoral general}

La expresión «Derecho electoral general» entiendo que es equivalente a la de «Ley electoral general» contenida en el artículo 81 de la Constitución y ya definido por las STC $38 / 83$ de 16 del V y 72/84 de 14 del VI, y por la Ley Orgánica del Régimen Electoral General. Es decir que en este supuesto se puede hablar de una equiparación total entre materia orgánica y exclusión de los Decretos-Leyes.

Para completar el estudio de los límites de los Decretos-Leyes es imprescindible referirse al alcance que el Tribunal constitucional ha otorgado al término "afectar", en cuanto que de ello se deriva una ampliación del campo de actuación mediante este instrumento mucho mayor del que parecería deducirse de los límites materiales y formales analizados hasta el momento.

Atendiendo a la pura literalidad de la norma quizás la interpretación más correcta es la ofrecida por SALAS ${ }^{10}$, al considerar que excluía no sólo una ordenación frontal o directa de esa materia, sino cualquier regulación incidental o indirecta. Pero con la amplitud de campos excluidos, tal definición hubiera convertido en inútil el instrumento gubernamental.

Asi el Tribunal Constitucional ha defendido un concepto absolutamente laxo del término "afectar", entendiendo como tal la regulación general de las materias y el contenido esencial o elementos esenciales de dicha regulación (STC 6/83, 111/83 y 60/86).

En conclusión se puede afirmar que la existencia de estrictos límites a la actuación mediante Decretos-Leyes, unida a la constante expansión de dicho instrumento ha obligado al Tribunal Constitucional a una complicadísima operación interpretativa del precepto que pivota sobre dos puntos de sentido abiertamente contrapuesto:

to La rigurosa concepción del significado del término "afectar" es expuesta por J. SaLAS, ob. cit., pág. 44 y resulta claro que no ha tenido recepción en nuestra doctrina jurisprudencial. 
- Mantenimiento absolutamente estricto e incluso extensivo de las restricciones a los Decretos-Leyes, en cuanto instrumentos «no normales" en relación a la Ley ordinaria.

- Significado muy laxo del término «afectar», que apenas tiene nada que ver con su acepción literal y que permite al Gobierno incidir, mediante Decretos-Leyes en esas mismas materias constitucionalmente excluidas.

El resultado de esta compleja operación es también complejo, pero en líneas generales favorable o ampliador de las posibilidades de acción gubernamental en utilización de esta técnica ${ }^{11}$.

\section{INTERVENCIÓN PARLAMENTARIA}

El artículo 86 de la Constitución establece un doble procedimiento sucesivo a la producción gubernamental de un Decreto-Ley:

Según su párrafo segundo en el plazo de 30 dias se debe producir un pronunciamiento expreso del Congreso de los Diputados (o su Diputación Permanente) sobre su convalidación o derrogación.

De acuerdo con el párrafo tercero en el mismo plazo las Cortes podrán tramitarlo como Proyecto de Ley por el procedimiento de urgencia.

Esta regulación ha dado lugar a una multiplicación de problemas interpretativos, entre los cuales se pueden destacar los siguientes:

a) ¿La doble via hay que entenderla necesariamente como acumulativa, como ha sancionado el Reglamento del Congreso, o cabe optar por una interpretación alternativa entre la convalidación y la tramitación como Ley?

b) ¿Cuál es la naturaleza, sentido y efectos de la convalidación, partiendo de que hay que entenderla más bien como una «homologación», como ha señalado la STC 6/83 de 4 del II, ya que no se trata de sanar una actuación viciada de nulidad? ¿Es un

1 El efecto expansivo de la interpretación dada al término «afectar» es señalado, entre otros, por F. GaRRido FALLA. Comentario al articulo 86, en Comentarios a la Constitución. Civitas. Madrid. 2." ed. 1985. págs. 1245 y ss. I. AstarloA, "Comentario...", págs. 478 y ss. J. PEREz RoYo, "La distribución..." cit. págs. 130 y ss. 
acto de control parlamentario, de carácter legislativo o mixto? ¿Qué forma debe revestir; una Ley o un simple acuerdo, como ha sancionado primero la práctica y más adelante el Reglamento del Congreso? ¿Cuál es el efecto fundamental de la convalidación?

c) ¿Cuál es el alcance y efectos del término «derogación»?

d) ¿Cuál es el sentido y efectos de su tramitación como Ley?

e) ¿Cuáles son las relaciones entre ambas técnicas de actuación parlamentaria, sobre todo de cara a su eventual control por el Tribunal Constitucional?

El tratamiento de este conjunto de problemas, que por otra parte se aborda en el texto del que esta exposición es un mero resumen, desbordaría con mucho. las pretensiones del presente trabajo, por lo que me voy a detener únicamente en dos de ellos; los efectos de la derogación y las relaciones entre Decreto-Ley convalidado y tramitado como Ley.

Comenzando por el primero de ellos hay que señalar que los Decretos-Leyes son normas con plena eficacia, pero que en el plazo de treinta días han de ser convalidados por el Congreso para salvar su nota esencial de provisionalidad. El problema fundamental es determinar cuáles son las consecuencias de la derogación, o de su no conversión tempestiva que hay que considerar a todos los efectos equivalente, y en concreto su alcance temporal; si afecta al Decreto-ley desde que surgió como norma gubernamental, ex tunc, o por el contrario desde que se produjo el acto formal o transcurso de los treinta días, ex nunc.

A favor del alcance meramente ex nunc de la derogación se pueden aportar los siguientes argumentos ${ }^{12}$.

a) La interpretación literal; derogar supone claramente efectos exnunc, y además se rechazó en la discusión del Reglamento del Congreso una enmienda del Grupo Socialista Catalán que hablaba de «anulación e ineficacia desde la fecha de su publicación».

b) La posición constitucional del Gobierno, cuyos actos gozan de una presunción de validez, y, al estar en este caso dotados de

12 A favor del carácter ex-nunc de la derogación se ha pronunciado, entre otros, GaRcia de Enterria/Fernández, Curso... cit. pág. 167. I. Astarloa, "Comentario..." cit. págs. 193 y ss. P. CRuz Villalon, "Tres sentencias..." cit. págs. 153 y ss. A. TORres del Moral, Principios de Derecho Constitucional. Atomo. Madrid. Tomo II. 1986. pág. 174. J. E. Soriano, «Algunos problemas...” cit. pág. 1099. 
"fuerza de ley», esta presunción sólo puede ser desvirtuada por el Tribunal Constitucional.

c) La clara configuración en el ordenamiento español de los Decretos-Leyes como competencia constitucionalmente «propia» del Gobierno.

d) Los problemas prácticos de la decadencia extunc con respecto a las situaciones jurídicas consolidadas durante el período de aparente vigencia de la norma gubernamental.

e) El estudio del único precedente existente a la práctica española de derogación de un Decreto-Ley, en concreto el 1/79 de 8 de enero, que prorrogaba la actuación de las Juntas de acuartelamiento, en cuya discusión parlamentaria en la Diputación permanente del Congreso se subraya la derogación como "pérdida de vigencia de la norma desde la publicación del acuerdo de derogación».

f) Por último, y aunque conceptualmente «anular» no es «derogar», conviene recordar que la única vez que el Tribunal Constitucional se ha enfrentado al problema de la fijación de los efectos temporales de una declaración de inconstitucionalidad de un Decreto-Ley, en la STC 60/86 de 20 del V, declara que «no ha razón alguna en este caso para retrotraer el efecto invalidante de las normas declaradas inconstitucionales al momento de entrada en vigor de las mismas».

A favor del carácter ex tunc de la derogación se afirman los siguientes argumentos ${ }^{13}$.

a) Se identifica la derogación con la ausencia de presupuestos constitucionales, lo cual creo que no es defendible en términos absolutos, en cuanto que, como lo prueba la práctica italiana, la inmensa mayoria de los Decretos-Leyes decaidos lo son por razones extrinsecas a su legalidad.

13 A favor del carácter ex-tunc de la derogación se han pronunciado, entre otros: J. Salas, Los Decretos... pág. 112 y ss. Montero/Garcla Morillo, El Control Parlamentario. Tecnos. Madrid, 1984 págs. 106 y ss. J. Pérez Royo, Las fuentes... cit. pág. 121. E. Alvarez Conde, El Régimen Politico español. Tecnos. Madrid, 1985. pág. 368. 
b) Se señala, y constituye sin duda una objeción de más peso, que afirmar la decadencia ex nunc de la norma gubernamental supondría reconocer un ámbito temporal de vigencia que dependeria exclusivamente de la voluntad gubernamental, y que ese ámbito estaría al margen de cualquier tipo de control.

Estas afirmaciones pueden ser matizadas en dos sentidos:

No es cierto, en términos absolutos que la derogación exnunc suponga siempre y necesariamente la existencia de un ámbito temporal regulado por normas «indeseadas por el Parlamento", ya que éste tiene la posibilidad de emanar normas retroactivas que eliminen ese período temporal, conviene recordar que la única irretroactividad constitucionalmente vedada por el artículo 9.3 es la que se refiere a las disposiciones sancionadoras no favorables o restrictivas de los derechos individuales.

No es en absoluto cierto que la derogación suponga la inatacabilidad jurídica de la norma. La STC 60/86 de 20 del V demuestra que el Tribunal puede entrar a analizar y declarar la inconstitucionalidad de un DecretoLey derogado, incluso a pesar de haberse producido un desestimiento formal de los recurrentes, sencillamente porque actúa en defensa objetiva del ordenamiento jurídico.

En conclusión creo que el estudio sistemático de la figura de la derogación muestra la existencia de un mayor número de elementos que conducen a una consideración ex nunc de sus efectos. A pesar de ello no se puede desconocer la existencia de objeciones de cierto peso a esta conclusión, y en definitiva se trata de un tema relativamente abierto.

El segundo de los problemas que plantea el régimen de intervención parlamentaria se refiere a la relación entre Decreto-Ley convalidado y tramitado como Ley.

En primer lugar es posible defender que Decreto-Ley y Ley son dos supuestos teóricos completamente distintos, por su origen, por sus límites materiales y. formales y por el resultado normativo final. De esta forma existirian en el ordenamiento jurídico dos normas completamente distintas, con sus propios vicios y causas de inconstitucionalidad y controlables separada y autónomamente.

A.un Decreto-Ley sucedería en el tiempo, derogándolo, una eventual Ley formal independiente, sin efectos retroactivos, salvo disposición expresa en contrario, y sin posibilidad de "efectos sanatorios" sobre los eventuales vicios del Decreto-Ley como norma gubernativa, los cuales habrían surgido en el momento de su producción y permanecen como tales inde- 
pendientemente de las vicisitudes posteriores de la norma ${ }^{14}$. Estariamos ante una sucesión-derogación puramente temporal, similar a la que se produce en el ordenamiento entre normas de igual rango.

Es teóricamente posible por el contrario concebir ambas normas formando parte de una única secuencia, de manera que el proceso culmina con una especie de "Ley de conversión", en el sentido italiano del término, que actuaría a modo de Bill of Indemnity anglosajón, y que convierte en inatacables los eventuales vicios del Decreto-Ley, sencillamente porque es sustituido, desde su origen, por la norma parlamentaria. Existiria por tanto un "efecto sanatorio" sobre la acción gubernamental, una especie de «perdón parlamentario" expresado en la aprobación de la Ley de conversión.

Entre los argumentos a favor de la primera de las concepciones expuestas se pueden esquematicamente señalar los siguientes:

a) El carácter de competencia «propia» y de ejercicio lícito de la acción gubernamental.

b) La decadencia ex nunc y no ex tunc de los Decretos-Leyes.

c) El tratarse la tramitación como Ley en nuestro ordenamiento de una vía puramente eventual, es decir existir Decretos-Leyes simplemente convalidados.

d) La plena disponibilidad parlamentaria en relación a la tramitación del proyecto de Ley, que puede provocar importantes diferencias materiales entre ambos textos o incluso que el último de ellos no llegue a ser aprobado.

e) La inaplicabilidad de los limites de los Decretos-Leyes a las Leyes que tienen como origen una de tales normas gubernamentales.

f) En definitiva la identidad de rango pero diferencias de especie entre un Decreto-Ley convalidado y una Ley.

14 La ineficacia sanatoria de las leyes ha sido defendida por la práctica totalidad de la doctrina. Vid, entre otros, I. AstARLOA, “Comentario...» cit. pág. 198 y ss. L. J. SEguRA GuIMARD, "El control..." cit. pág. 345 y sS. P. CRUz VILLALON, "Tres sentencias..." cit. págs. 154 y ss. A. ToRres del Moral, Principios... pág. 175. Como situación de hecho, ante la Jurisprudencia del Tribunal Constitucional, pero de forma muy crítica. J. PÉREZ RoYo se ve obligado a aceptar el efecto contrario señalando que «la tramitación como ley borra caso por completo todo vicio de inconstitucionalidad, esto no implicitamente pero si explicitamente sucede en la STC 2 de diciembre de 1983". "La distribución..." cit. pág. 142. 
Todo ello debería llevar a admitir en nuestro ordenamiento jurídico el siguiente esquema relacional entre ambos instrumentos:

- Ambas normas pueden tener vicios autónomos, sin que se pueda defender una comunicación necesaria entre ellas a estos efectos.

- Ambas normas tienen un tratamiento procesal distinto, en el sentido de que la impugnación del Decreto-Ley no conlleva necesariamente la de la Ley ni viceversa.

- La Ley en principio no es retroactiva, aunque, en las condiciones del artículo 9.3 de la Constitución, pueden hacerse retroactivos algunos de sus efectos mediante una expresa remisión.

- No se puede hablar de ningún tipo de "efectos sanatorios" de la Ley sobre el Decreto-Ley, que si no se adecuaba a los preceptos constitucionales, continuará sin hacerlo como tal Decreto-Ley, a pesar de que su contenido material se haya convertido en Ley.

Sin embargo la controvertida y criticable Sentencia del Tribunal Constitucional 111/83 sobre el caso RUMASA, a la que resulta perfectamente aplicable el aforismo americano "grandes casos crean mala jurisprudencia", se mueve en una dirección distinta y a mi entender absolutamente injustificable al analizar exclusivamente la constitucionalidad de aquellas normas no contenidas en la Ley, predicando un «efecto sanatorio» de ésta, que resulta de especial gravedad no sólo por la confusión que provoca a la hora de delimitar los instrumentos normativos del Decreto-Ley y la Ley, sino porque probablemente elimina todo límite específico a la acción normativa del Gobierno, produciendo una profunda modificación del sentido de los Decretos-Leyes, de importantes consecuencias desde el punto de vista democrático y de la estructura de poderes con respecto a cómo ha sido establecida por nuestra Norma fundamental.

\section{CONTROL POR EL TRIBUNAL CONSTITUCIONAL}

Muy esquemáticamente podemos señalar que las notas fundamentales que han caracterizado la actividad del Tribunal Constitucional en relación a los Decretos-Leyes son las siguientes:

Reconociendo grandes dosis de amplitud en la interpretación realizada por el Gobierno, sin embargo ha defendido en todo momento que el enunciado del artículo 86 constituye un conjunto de auténticos límites jurídico-constitucionales de la actuación gubernamental, y como tales controlables por su jurisprudencia. Se trata de una concepción de excepcional 
importancia porque supone la garantía máxima frente a cualquier posibilidad de abuso en la utilización del instrumento mediante una connivencia del Gobierno y la mayoría parlamentaria, y que contrasta fuertemente con la experiencia italiana, país en el que, hasta 1982, solamente en una ocasión, en concreto en la sentencia de 30 de marzo de 1977, se le pide a la Corte Constitucional a través de una Cuestión de Constitucionalidad que se pronuncie sobre la existencia de los presupuestos de extraordinaria necesidad y urgencia, pero no llegó a hacerlo «por falta de relevancia para el caso concreto".

Existencia en el ordenamiento español de un control autónomo sobre los Decretos-Leyes, a diferencia también del caso italiano, en el que sólo existe un supuesto, la Sentencia 75/67 de 3 de julio, de control autónomo. Esta diferencia se debe en parte al doble mecanismo de la convalidación/ tramitación como Ley, pero sobre todo a la consideración de ambas normas como instrumentos independientes, aunque es cierto que este último aspecto ha quedado en buena medida en entredicho tras la polémica sentencia de RUMASA y la supuesta eficacia sanatoria de la Ley en ella contenida, problema al que acabamos de referirnos.

A pesar de ello se puede afirmar que se ha producido un control mucho más adecuado de la facultad gubernamental en la actuación judicial española que en la italiana, y que en este aspecto, que hay que considerar esencial a la hora de emitir un juicio global, nuestro ordenamiento se ha mostrado netamente superior, mucho más acorde al binomio responsabilidad-control que debe caracterizar el funcionamiento de las instituciones democráticas.

\section{UTILIZACION DE LOS DECRETOS-LEYES EN LA II LEGISLATURA}

Un estudio empírico de la utilización de los Decretos-Leyes a lo largo de la Il Legislatura ofrece, esquemáticamente las siguientes conclusiones:

1) Número relativamente alto de Decretos-Leyes; 40 , lo que supone que una vez cada 33,45 dias el Gobierno consideró de "extraordinaria y urgente necesidad» su actuación normativa primaria, pero, en disminución progresiva, ya que en la primera se produjeron 77 , es decir 1 cada 18,18 días, y desde enero del 86 a junio del 87 sólo se han producido, 4, uno cada 133 días.

2) Porcentaje relativamente bajo de Decretos-Leyes en el conjunto de normas con rango de Ley, ya que sólo suponen el 16,33 por 100 de las producidas en la Legislatura. 
3) Predominio material de los Decretos-Leyes derivados de la «crisis económica», que representan un 32,5 por 100 del total, lo que confirma su utilización como instrumento de política económica.

4) Cierta relajación gubernamental a la hora de publicar en el Boletín Oficial del Estado los Decretos-Leyes, lo que seria un indicio de la ausencia de «urgencia»; el tiempo medio es de 5,67 días, pero existe un caso, el 4/83 con una dilación de 27 días, y sobre todo relajación, o algo más que relajación a la hora de explicar las razones de la "urgencia y necesidad» ante el Congreso, que es una obligación Reglamentaria incumplida nada menos que en el 25 por 100 de las ocasiones.

5) Actuación parlamentaria con gran celeridad en el acto de convalidación, 16,76 dias materiales como media, frente a los 30 dias hábiles constitucionalmente posibles, existiendo incluso un supuesto, el 15/84 que fue convalidado al día siguiente de su publicación en el $B O E$. Adẹmás en ella es constatable una fuerte oposición a las medidas gubernamentales, ya que sólo el 30 por 100 de los Decretos-Leyes, excluyendo los que se refieren a catástrofes naturales, fueron aprobados con más votos a favor de los que corresponderían a la mayoría socialista.

6) Sin embargo, existencia de casos significativos, los DecretosLeyes 14 y 15/84, de práctica ausencia de actividad parlamentaria, al aprobarse la convalidación por asentimiento, sin explicación y defensa por el Gobierno y sin turnos a favor ni en contra de la medida.

7) Bajísimo índice de Decretos-Leyes tramitados como Leyes, sólo el 32,50 por 100 , dato especialmente grave si consideramos que en el 81,4 por 100 de las ocasiones la mayoría socialista negó al Congreso el pleno ejercicio de su capacidad, incluida la presentación de enmiendas, y consecuentemente mantuvo en el ordenamiento normas con rango de Ley sobre las que apenas existió actividad parlamentaria contra la postura de algún grupo parlamentario, $y$ en ocasiones frente a todos ellos.

\section{CONCLUSIÓN}

El trabajo parte de la consideración de los Decretos-Leyes como poderes «propios» del Gobierno, de un Gobierno que está legitimado de- 
mocráticamente para, en circunstancias de necesidad, decidir la sustitución del Parlamento en la regulación provisional de ciertas materias, pero constatando al mismo tiempo que la constitucionalización de esta facultad supone un intento de delimitar procedimental y materialmente esa actividad normativa primaria.

Con ello se establece el dualismo característico del Estado democrático; el Gobierno tiene capacidad jurídica para la producción de Decretos-Leyes, pero a ella se contrapone su responsabilidad parlamentaria, y, en última instancia el control del Tribunal Constitucional.

Asi las claves para juzgar el carácter democrático de este tipo de instrumento pueden ser resumidas en dos preguntas fundamentales:

¿Existen suficientes garantias para las minorias de que el procedimiento de control parlamentario de las normas primarias del Gobierno reúne las características, de contradicción, de publicidad, que requiere toda actividad parlamentaria, o es, por el contrario un mero requisito formal para salvar exigencias, también formales, derivadas de una concepción superada en la práctica de la separación de poderes?

¿Existe un procedimiento jurídico ante el Tribunal Constitucional mediante el cuál las minorias puedan hacer valer sus derechos, y en última instancia el carácter normativo de la Constitución, frente a una acción extralimitada del Gobierno con la connivencia de la mayoría parlamentaria?

El resultado del trabajo muestra que si bien la actuación del Tribunal Constitucional como garante de la Constitución puede ser considerada en líneas generales satisfactoria, sin embargo el procedimiento de la convalidación no ofrece las suficientes garantias para la actuación parlamentaria, lo que constituye, desde mi punto de vista, uno de los mayores problemas para la consideración de los Decretos-Leyes como instrumentos plenamente democráticos en el ordenamiento jurídico español. 